\title{
Glycemic Control and Prevention of Diabetic Complications in Low- and Middle-Income Countries: An Expert Opinion
}

\author{
Pablo Aschner · Gagik Galstyan • Dilek G. Yavuz • Leon Litwak • \\ Guillermo Gonzalez-Galvez • Freddy Goldberg-Eliaschewitz • \\ Khadija Hafidh · Khier Djaballah · Shih-Te Tu • Ambika G. Unnikrishnan • \\ Kamlesh Khunti
}

Received: September 30, 2020 / Accepted: January 6, 2021 / Published online: April 10, 2021

(C) The Author(s) 2021

\section{ABSTRACT}

Introduction: Trends on glycemic control and diabetes complications are known for high-income countries, but comprehensive data from low- and middle-income countries (LMIC) are lacking.

Methods: This is an expert opinion based on two retrospective studies. Here we examine the recent subset analysis of relevant data from the IDMPS Wave 7 (International Diabetes

P. Aschner $(\bowtie)$

Javeriana University School of Medicine and San Ignacio University Hospital, Bogota, Colombia

e-mail: pabloaschner@gmail.com

G. Galstyan

Endocrinology Research Center, Moscow, Russia

D. G. Yavuz

Department of Endocrinology and Metabolism,

Marmara University School of Medicine, Istanbul, Turkey

L. Litwak

Endocrine, Metabolism and Nuclear Medicine Service, Diabetes Section, Hospital Italiano de Buenos Aires, Buenos Aires, Argentina

G. Gonzalez-Galvez

Instituto Jalisciense de Investigación en Diabetes Y Obesidad, Guadalajara, Jalisco, Mexico

F. Goldberg-Eliaschewitz

CPClin Clinical Research Center, Sao Paulo, Brazil
Management-Practices Study, 2015-2016) and the GOAL study conducted in multiple LMICs. Results: Wave 7 sub-analysis was performed in 6113 people with type 2 diabetes from 24 LMIC. Poorly controlled diabetes (hemogloblin A1c $[\mathrm{HbA} 1 \mathrm{c}] \geq 7 \%$ ) was found in 58.6, 73.0 and $78.3 \%$ of participants with diabetes duration of $<5,5-12$ and $>12$ years, respectively (in association with a high prevalence of macroand microvascular complications). Moreover, $37.7 \%$ of participants with diabetes duration of 5-12 years were treated only with oral antihyperglycemic drugs. The GOAL study

\section{K. Hafidh}

Rashid Hospital, Dubai, United Arab Emirates

K. Djaballah

Sanofi, Paris, France

\section{S.-T. Tu}

Division of Endocrinology and Metabolism, Department of Internal Medicine, Changhua Christian Hospital, Changhua, Taiwan

A. G. Unnikrishnan

Chellaram Diabetes Institute, Pune, India

K. Khunti

Diabetes Research Centre, University of Leicester, Leicester, UK 
investigated the efficacy of insulin in 2704 poorly controlled participants (mean HbA1c 9.7\%; diabetes duration $10.1 \pm 6.7$ years; 10 LMIC). A significant $2 \%$ reduction in mean HbA1c levels was observed after 12 months of treatment. Only $7.2 \%$ of participants experienced a symptomatic episode of hypoglycemia (nocturnal or severe hypoglycemia events were infrequent).

Conclusion: The rate of well-controlled participants (HbA1c $<7.0 \%)$ in the Wave 7 subanalysis was lower than that observed in the USA (NHANES survey) or in European countries (GUIDANCE study), and the incidence of microvascular complications was higher. The GOAL study showed that insulin treatment improves glycemic control and reduces this gap. The Expert Panel recommends intensifying diabetes treatment as soon as possible, as well as patients' education and other preventive measures, initiatives which require modest costs compared to hospitalization and treatment of diabetes complications.

Keywords: Diabetes complications; Diabetes mellitus; Glycemic control; Health policy; Health promotion; Health services development; Human resources; Low- and middle-income countries; Nutrition; Obesity

\section{Key Summary Points}

\section{Why carry out this study?}

Trends on glycemic control are known for high-income countries, but comprehensive data from low- and middle-income countries (LMIC) are lacking

We evaluated data from Wave 7 , the most recent survey (2015-2016) of the IDMPS (International Diabetes ManagementPractices Study) and the GOAL study of insulin treatment initiation or intensification in poorly controlled people with type 2 diabetes

\section{What was learned from the study?}

A Wave 7 sub-analysis found a $32-36 \%$ lower rate of well-controlled diabetes (hemoglobin A1c [HbA1c] < 7.0\%) compared to the USA or European countries, and the rate of microvascular complications was almost double. The GOAL study showed that insulin initiation or intensification reduces mean HbA1c levels by $2 \%$ after 12 months of treatment

We recommend intensifying diabetes treatment as soon as possible, as well as patients' education and other preventive measures, initiatives which require modest costs compared to hospitalization and treatment of diabetes complications

\section{DIGITAL FEATURES}

This article is published with digital features, including a summary slide, to facilitate understanding of the article. To view digital features for this article go to https://doi.org/10.6084/ m9.figshare.13525556.

\section{INTRODUCTION}

Worldwide, the number of people with diabetes mellitus increased from 108 million in 1980 to 422 million in 2014 , and about $79 \%$ of these people are living in low- and middle-income countries (LMIC) [1-3]. As of 2019, LMIC were defined by the World Bank criteria based on the Gross National Income (GNI) per capita in 2018, as (1) low-income economies ( $\leq$ US\$1025); lower middle-income economies (US\$1026-3995) and upper middle-income economies (US\$3996-12,375). Between 2010 and 2030, the number of adults with type 2 diabetes (T2D) is expected to increase faster in LMIC (69\% increase) than in high-income countries (20\%) [3].

Trends on diabetes care are known for highincome countries [4], but data from LMICs are 
currently limited. Indeed, public health measures to reduce diabetes-related morbidity and mortality in those countries are hampered by the poor understanding of the local resources to implement healthcare intervention programs and improve diabetes care $[5,6]$.

The International Diabetes Management Practice Survey (IDPMS) is a global observational study conducted in real-world setting aimed at exploring patient profiles, management practices, and patterns of care across time in adult patients with type 1 diabetes mellitus (T1D) or T2D predominantly from LMIC [5-10]. GOAL is another international, multicenter, observational study that evaluated clinical and non-clinical predictive factors for achieving glycemic control in people with $\mathrm{T} 2 \mathrm{D}$ in ten LMICs [11]. Recently, a group of diabetes experts began evaluating: (1) a sub-analysis of Wave 7, the most recent survey (2015-2016) of the IDMPS [12] and (2) the GOAL study of insulin treatment initiation or intensification in poorly controlled people with T2D [11]. The aim of this evaluation was to assess therapeutic inertia and highlight the need for generating more data to better understand the reasons for therapeutic inertia and how to address this issue. Herein, we present the opinion of a group of experts on therapeutic inertia and an update of the 'real life' situation in the LMICs evaluated.

\section{METHODS}

\section{Sub-Analysis of The IDMPS Wave 7 Survey}

The IDMPS program has been conducted in a series of waves since 2005 [5-10], each wave including a cross-sectional survey of participants' profiles and trends of care management in persons with T1D and T2D in LMIC. Relevant information on these IDMPS waves has been already published [5-10].

Wave 7 is the most recent survey (2015-2016) from the IDMPS study program. It was conducted in 24 countries across South Asia (Bangladesh, India), Eurasia (Russia, Ukraine), the Middle East (Iran, Iraq, Jordan, Kuwait, Lebanon, Pakistan, Saudi Arabia, United Arab
Emirates) and Africa (Algeria, Cameroon, Democratic Republic of Congo, Egypt, Ivory Coast, Kenya, Madagascar, Morocco, Nigeria, Senegal, South Africa, Tunisia). The investigating physicians were asked to enroll the first ten adult subjects with T2D and the first five adult subjects with T1D who attended their office over a 2-week recruitment period.

Duration of diabetes (time since diagnosis) plays a major role in both glycemic control and diabetic complications [13, 14]. A complementary analysis of Wave 7 data was performed to investigate the impact of diabetes duration on patient's outcomes in LMIC. Participants were stratified to three groups according to time since diabetes diagnosis: $\leq 5$ years (group 1), between 5-12 years (group 2) and $>12$ years (group 3). Glycemic control and diabetic complications were investigated in each group as a function of the diabetes treatment regimen.

\section{GOAL Study}

A prospective, real-world practice study (GOAL) was previously conducted in 2704 participants from South Asia (Bangladesh, India, Pakistan), Middle East (Israel, Saudi Arabia, United Arab Emirates, Iran, Lebanon) and Africa (Egypt and South Africa) to evaluate the efficacy of insulin therapy patients with poorly controlled T2D [11].

\section{Compliance with Ethics Guidelines}

This article is based on previously conducted studies and does not contain any studies with human participants or animals performed by any of the authors.

\section{RESULTS}

\section{Impact of Diabetes Duration on Glycemic Control And Diabetic Complications (IDMPS Wave 7 Survey)}

A total of 6113 participants with T2D had completed relevant data and were included in the analysis. The mean age was 58.1 years, 
Table 1 Demographic and clinical characteristics of participants (Wave 7 subanalysis)

\begin{tabular}{llll}
\hline Participant characteristics & Group 1 $^{\mathbf{a}}(\boldsymbol{n}=\mathbf{2 0 9 2})$ & Group 2 $^{\mathbf{a}}(\boldsymbol{n}=\mathbf{2 1 4 7})$ & Group 3 $^{\mathbf{a}}(\boldsymbol{n}=\mathbf{1 8 7 4})$ \\
\hline Age (years) & $52.8(11.3)$ & $57.0(10.3)$ & $62.4(9.3)$ \\
Proportion female (\%) & 49.9 & 52.8 & 54.3 \\
Time since diabetes diagnosis (years) & $2.76 \pm 1.50$ & $8.74 \pm 2.02$ & $18.8 \pm 5.6$ \\
Body mass index $\left(\mathrm{kg} / \mathrm{m}^{2}\right)$ & $29.6(5.6)$ & $29.9(5.5)$ & $29.9(5.4)$ \\
Last HbAlc $\%$ level) & $7.77(2.01)$ & $8.15(1.86)$ & $8.23(1.70)$ \\
At target HbAlc $<7 \%$ & 41.4 & 27.0 & 21.7 \\
Fasting blood glucose $\leq 100 \mathrm{~g} / \mathrm{dL}$ & 17.2 & 14.7 & 12.4 \\
Microvascular complications $(\%)$ & & & 63.8 \\
Any & 32.1 & 50.7 & 37.6 \\
Retinopathy & 8.7 & 21.6 & 76.4 \\
Cardiovascular disease & 58.4 & 70.3 & 37.4 \\
Diabetes medication $(\%)$ & & & 46.6 \\
OADs alone & 80.1 & 58.4 & 16.0 \\
Insulin + OAD & 14.5 & 32.3 & 9.3 \\
Insulin alone & 5.4 & &
\end{tabular}

Data are presented as mean with the standard deviation (SD) in parentheses or as the percentage (\%) of participants HbAlc Hemoglobin A1c, OADs oral antihyperglycemic drugs

${ }^{a}$ Groups classified according to duration of diabetes: group 1, diabetes duration $\leq 5$ years; group 2, diabetes duration $5-12$ years; group 3 , diabetes duration $>12$ years

$47.7 \%$ were males and mean hemoglobin A1c (HbA1c) was $8.2 \%$. The distribution of participants by region was: South Asia $(n=660$, $10.8 \%)$, Eurasia $(n=1296,21.2 \%)$, Middle East $(n=1838,30.1 \%)$ and Africa $(n=2319,37.9 \%)$.

Of the 6113 participants, based on duration of diabetes 2092 belonged to group 1, 2147 to group 2 and 1874 to group 3 (Table 1), with $58.6,73.0$ and $78.3 \%$ in each group, respectively, having poorly controlled diabetes $(\mathrm{HbA} 1 \mathrm{c} \geq 7 \%)$. These differences were associated with the prevalence of macro- and microvascular complications (Table 1). In all groups, a high proportion of participants were treated with oral antihyperglycemic drugs (OADs) alone $(80.1 \%$ in group $1,58.4 \%$ in group 2 and $37.4 \%$ in group 3 ) despite poorly controlled diabetes in most participants.

\section{Therapeutic Inertia}

A large proportion of participants with long diabetes duration ( $\geq 5$ years) had an insufficient glycemic control (HbA1c $\geq 7.0 \%)$, but were treated with OADs alone (Fig. 1). This was the case for $64.5 \%$ of participants with 5-12 years of diabetes duration and $67.1 \%$ of participants with more than 12 years of diabetes duration (Fig. 1).

\section{GOAL Study}

\section{Demographic and Clinical Aspects}

Participants included in the GOAL study had a mean ( \pm standard deviation) age of $54.6 \pm 10.6$ years, long mean diabetes duration (10.1 \pm 6.7 years), poorly controlled diabetes (mean HbA1c 9.7\%; mean fasting blood glucose $196.8 \mathrm{mg} / \mathrm{dL}$ ) and they required insulin initiation/up-titration, or insulin intensification 


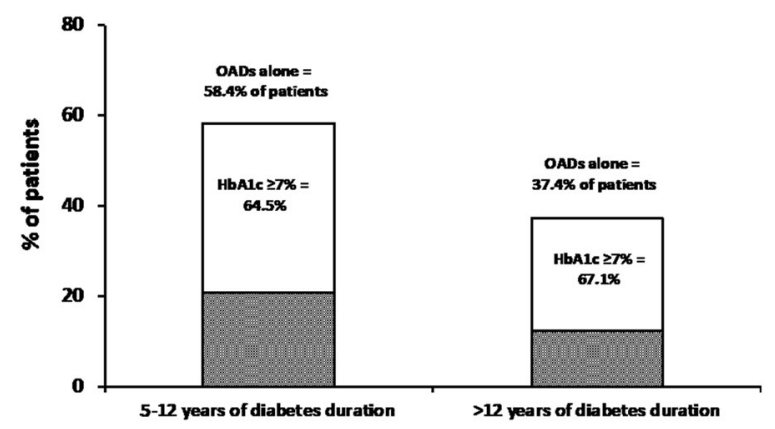

Fig. 1 Therapeutic inertia in people with type 2 diabetes from low- and middle-income countries (LMIC) (Wave 7 sub-analysis). A large proportion of patients with diabetes duration of $\geq 6$ years were treated with oral antihyperglycemic drugs $(O A D s)$ alone, despite insufficient glycemic control (hemoglobin Alc $[H b A 1 c] \geq 7.0 \%$ )

(basal insulin $+1-3$ bolus of rapid-acting insulin). A significant proportion of participants $(55.9 \%)$ had complications associated with diabetes. Of these, 87.9 and $32.9 \%$ had micro- and macrovascular complications, respectively.

\section{Therapeutic inertia}

At the time of inclusion, $63.3 \%$ of participants were treated with OADs alone, $8.8 \%$ with insulin alone and $27.9 \%$ with OADs + insulin. Among insulin-treated participants, 38.8, 35.6 and $17.1 \%$ were given basal insulin alone, premix insulin and basal + prandial insulin, respectively.

\section{Insulin efficacy}

At the end of the inclusion visit, $85.4 \%$ of participants were prescribed both OADs and insulin, and $14.6 \%$ received insulin alone (insulin glargine was the most frequently prescribed insulin treatment, 96\%). Insulin initiation or intensification was associated with significant reductions in HbA1c levels $(-1.7 \%$ and $-2 \%$ at 6 and 12 months of follow up, respectively).

\section{Predictive Factors of Therapeutic Efficacy with Insulin}

The GOAL study investigated predictive factors for achieving glycemic control with insulin therapy [11]. At 6 and 12 months, advanced age, Caucasian ethnicity, shorter duration of diabetes and lower baseline HbA1c were statistically significant predictive factors $(P$ $\leq 0.0001)$ to achieve the glycemic goals targeted by the treating physician $(\mathrm{HbA} 1 \mathrm{c}<7 \%)$.

\section{Hypoglycemia}

Only $7.2 \%$ of participants experienced a symptomatic episode of hypoglycemia. Nocturnal or severe hypoglycemia were infrequent and only three participants suffered a serious episode of hypoglycemia.

\section{DISCUSSION}

The IDMPS Wave 7 sub-analysis showed that many people with T2D in LMIC are treated with OADs alone despite poor glycemic control. In addition, the GOAL study showed that insulin initiation or intensification significantly reduced HbA1c levels (-2\%) in poorly controlled participants [11]. The panel of experts compared these results with those obtained in high-income countries in order to define plausible preventive strategies.

\section{Therapeutic Inertia in LMIC Compared to High-Income Countries}

The results of the IDMPS Wave 7 sub-analysis were compared with those obtained in Western countries, where trends on glycemic control are well known $[15,16]$. The rate of insufficient

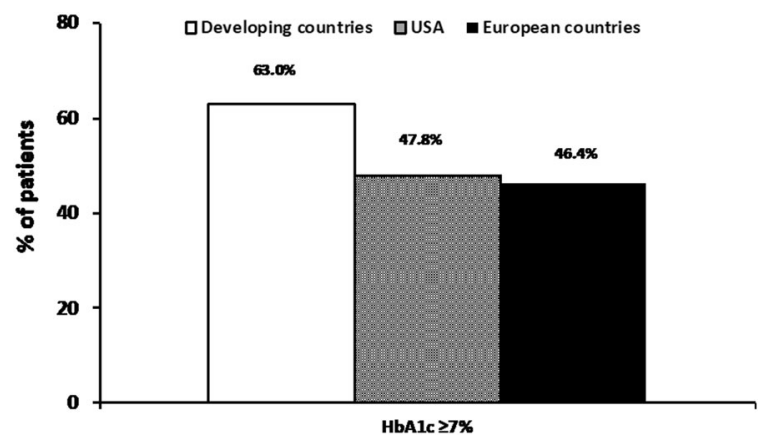

Fig. 2 Glycemic control in LMIC versus European countries and the USA. Data for European countries and the USA were obtained from the GUIDANCE study [16] and the NHANES survey [15], respectively. LMIC had a lower proportion of well-controlled patients $(\mathrm{HbAlc}<7.0 \%)$ 
glycemic control in that sub-analysis, 63\% in patients with diabetes duration between 5 and 12 years, was higher than that observed in the NHANES survey in the USA [15] and in the GUIDANCE study in European countries [16] (Fig. 2). These data, as well as the GOAL data, suggest significant opportunities for improving glycemic control in LMIC.

\section{Barriers to Insulin Therapy}

In the UK, a retrospective cohort study based on 81,573 people with T2D [17] showed that many of the patients experienced years of inadequate glycemic control due to delays in treatment intensification, especially when insulin treatment was needed. Moreover, once insulin therapy has been initiated, many patients fail to reach glycemic targets [18]. Glycemic control is suboptimal across geographic regions and in both low- and higher-income countries, and delays of 3 years or more are frequent before an initiation or intensification of diabetes treatment $[19,20]$.

Multiple factors related to the patient and the physician contribute to the resistance to insulin initiation, titration and/or intensification stages [21]. The reasons for this include poor access to medicines and medical care, fear of daily injections and hypoglycemia by the patient, poor communication, lack of experience in primary care by the physician and lack of time and/or resources [21].

In LMIC, Casciano et al. [9] showed that the possibility of oral administration instead of injectable therapies was a determining factor for not initiating insulin, while the risk of hypoglycemia symptoms had a much lower influence on treatment decision. Experience with insulin treatment and diabetes education significantly improved insulin use [9]. Aschner et al. [22] showed that fear of hypoglycemia, lack of insulin titration and costs were the most common reasons for not intensifying insulin therapy. Finally, patients' education modestly, but significantly improved the number of patients achieving HbA1c target values in LMIC ( 38.1 vs. $35.8 \%$ without diabetes education) and increased their insulin use [10].

\section{Diabetic Complications and Mortality in LMIC Versus High Income Countries}

Diabetes is a silent disease for many patients, which increases cardiovascular mortality in the long-term and/or generating serious microvascular complications, such as kidney failure, retinopathy and severe foot infections leading to amputation [4]. Poor glycemic control is common in patients in developing countries as compared to those in developed ones. For example, the rate of insufficient glycemic control reported in this IDMPS Wave 7 sub-analysis, namely $63 \%$ in patients with diabetes duration between 5 and 12 years, was higher than that observed in the NHANES survey in the USA [15] and the GUIDANCE study in European countries [16] (Fig. 2). Similarly, in LMIC a relatively lower percentage of patients were screened for diabetes-related complications, such as retinopathy, as compared to evaluations made in the USA and Europe (Fig. 3). Additionally, the rate of microvascular diabetes complications in the Wave 7 population $(50.7 \%$ for a diabetes duration between 5 and 12 years) was much higher than the rate observed for a similar diabetes duration in European countries (27.7\%) [16].

The estimation of mortality due to diabetes in some LMIC has been problematic since no reliable data are available and also because people with diabetes are more frequently reported to die of "cardiovascular disease" or

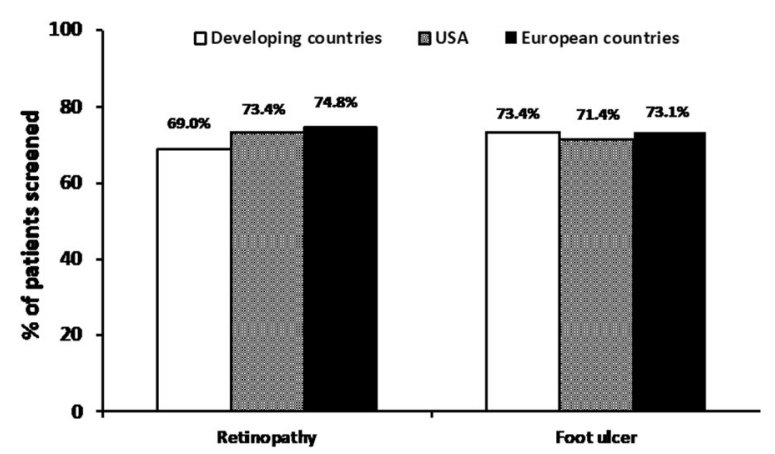

Fig. 3 Annual screening rates for diabetic retinopathy and foot ulcer. Screening values in LMIC [28] compare well with those reported for European countries (GUIDANCE study) [16] and for the USA (NHANES survey) (15) 
"kidney failure," instead of "a diabetes complication" [23]. Roglic and Unwin [24] used a computerized disease model and estimated that approximately four million deaths related to diabetes occur each year, with $80 \%$ of them in LMIC. Global comparisons have also shown that some countries experience high rates of hypoglycemia-related mortality [25]. To our knowledge, the influence of glycemic control on diabetes mortality has not been investigated in LMIC.

\section{Preventive Practices}

With proper changes in lifestyle, as well as early diagnosis and intervention, many people with diabetes can delay the onset of complications and attenuate tissue damage [26, 27]. In particular, annual screening for chronic diabetes complications is recommended in treatment guidelines [1].

In LMIC, Gagliardino et al. [28] reported annual screening rates of $69.0 \%$ for retinopathy (retina examination), $62.5 \%$ for neuropathy (monofilament test), $83.9 \%$ for nephropathy (blood or urine test) and $73.4 \%$ for foot ulcer. It is of interest to note that while screening values for retinopathy in LMICs are lower than those reported for European countries (GUIDANCE study) [16] and for the USA (NHANES survey) [15], screening for foot ulcer compares well with those noted in the developed countries (Fig. 3). Moreover, Gagliardino et al. [10] also showed educated patients had significantly lower rates of both foot ulcer $(-31 \%)$ and peripheral vascular disease $(-26 \%)$, and higher insulin use.

\section{Role of Patient and Healthcare Education for Better Glycemic Control in LMICs}

Previous studies have indicated that lack of proper education related to diabetes is a predictive factor for poor glycemic control [11]. For example, in the IDMPS Wave 5 survey, although $78.3 \%$ of the patient population has received diabetes education, very few patients received a structured educational course by certified diabetes instructors; rather, the majority received it from physicians [29]. Moreover, only half of the population in these LMICs followed a healthy diet and had a regular physical exercise plan [11]. This poor awareness of diabetes disease management is clearly reflected by finding that $<50 \%$ of the patients achieved the target HbA1c of $<7 \%$ [29]. Similar observations have been reported from other studies, highlighting the importance of disease education as a management strategy for better glycemic outcomes. Thus, there is a need for a more structured and systematic education of patients with respect to how to manage their disease so as to avoid uncontrolled glycemic control over the long term, with the ultimate aim to prevent diabetes disease-related complications.

\section{Strengths and Limitations}

This expert opinion reflects the existing scenario of diabetes prevalence, incidence and diabetes care in LMICs, based on an analysis of the two recent and large registries performed in some of the developing countries from different regions of the world. The strength of this expert opinion is that it is based on the two studies with a large sample size and a global representation outside Europe and North America, and is instrumental in evaluating the prevailing diabetes conditions in developing countries as compared to the developed countries. However, the major limitation of this expert opinion is that it is representative in nature and allows only a summation of data rather than actual measurements.

\section{Future Perspectives}

In LMIC, many people with diabetes receive a late diagnosis, at the time when patients present with retinopathy, nephropathy, foot ulceration and other complications, with a consequent loss of treatment efficacy [30]. Most of the direct costs of T2D treatment are due to diabetes complications [8, 31-35]. This is particularly true in the case of hospitalizations due to diabetes complications, which mobilize many human resources and require expensive medical procedures (i.e. leg amputations) $[5,36]$. Therefore, the burden of diabetic complications 
in LMIC represents a dramatic challenge for healthcare providers and patients.

The costs of improving glycemic control and other preventive measures are less than the costs of inpatient hospital care and the treatment of diabetes complications $(60 \%$ of the total medical costs) [37]. Moreover, health expenditure attributable to diabetes is much lower in LMIC than in high-income countries [38]. Improving both glycemic control and a patient's education should be the short-term strategies of choice in LMICs.

Finally, specific clinical practice recommendations for LMIC are urgently needed. We suggest that healthcare providers focus on appropriate treatment guidelines (American Diabetes Association/European Association for the study of Diabetes and recommendations therein and on local country recommendations/consensus guidelines) which emphasize early diagnosis, systematic screening for complications and proper and timely treatment intensification.

\section{CONCLUSIONS}

The rate of well-controlled participants (HbA1c $<7.0 \%)$ in the Wave 7 sub-analysis was lower than that observed in the USA (NHANES survey) or in European countries (GUIDANCE study), and the incidence of microvascular complications was higher. The GOAL study showed that insulin treatment improves glycemic control and may reduce this gap. The Expert Panel recommends intensifying diabetes treatment as soon as possible, as well as intensifying patients' education and other preventive measures, as these interventions require modest costs compared to the costs of hospitalization and treatment of diabetes complications.

\section{ACKNOWLEDGEMENTS}

Funding. Sanofi funded the Wave 7-subanalysis and the GOAL study. Medical writing activities and the journals rapid service fee were also funded by Sanofi.
Medical Writing and Editorial Assistance. The authors thank R.P. Garay (Pharmacology and Therapeutics, Craven, Villemoissonsur-Orge, France) for his help in writing the article and Dr. Sai Krishnaveni Chevooru (Sanofi) for assistance with writing and editing, which was funded by Sanofi.

Authorship. All named authors meet the International Committee of Medical Journal Editors (ICMJE) criteria for authorship for this article, take responsibility for the integrity of the work as a whole, and have given their approval for this version to be published.

Disclosures. Pablo Aschner has served as a consultant for and received speaker fees from AstraZeneca, Boehringer Ingelheim, Eli Lilly, Merck Sharp \& Dohme, Novo Nordisk and Sanofi-Aventis; and has served on an advisory board for Merck Sharp \& Dohme and SanofiAventis. Gagik Galstyan has served on an advisory board for MSD, Astra Zeneka, Novo Nordisk, Sanofi, Abbott and Pfizer; and received speaker fees Speakers from Eli Lilly, Novo Nordisk, Sanofi, Novartis, Berlin Chemie, MSD, Boehringer Ingelheim, Astra Zeneca, Amgen, LifeScan, Servier and Takeda. Dilek Gogas-Yavuz has received honoraria from and has participated in clinical trials for Novo Nordisk, SanofiAventis, Novartis, Amgen and Pfizer. Leon Litwak is a member of the international advisory board of Latam, Eli Lilly and Sanofi; serves on the local advisory boards of Novo Nordisk, Sanofi, Boehringer Ingelheim, Astra-Zeneca; and is Principal Investigator and speaker for Eli Lilly, Novo Nordisk, Novartis, Glaxo, Takeda, Pfizer, Merck Sharp \& Dome, Amgen, Roche and Astra-Zeneca. Guillermo González-Gálvez has served as a consultant for and received speaker fees from Merck Sharp \& Dohme, Novo Nordisk, Sanofi, AstraZeneca, Boehringer Ingelheim, AMGEN and Stendhal; and has served on an advisory board for AstraZeneca, Boehringer-Ingelheim, Novo Nordisk, Sanofi, Merck Sharp \& Dohme, AMGEN and Stendhal. Freddy Goldberg Eliaschewitz has served as a consultant for and received speaker fees from Amgen, AstraZeneca, Bayer, Eli Lilly, Merck Sharp \& Dohme, Novo Nordisk and Sanofi-Aventis; has served on 
advisory boards for AstraZeneca, Eli Lilly, Novo Nordisk and Sanofi-Aventis; and has received grants to support investigations from AstraZeneca, Boehringer Ingelheim, Eli Lilly, Novartis, Novo Nordisk and Sanofi-Aventis. Khadija Hafidh was a consultant and received speaker fees from AstraZeneca, Boehringer Ingelheim, Eli Lilly, Servier, Merck Sharp \& Dohme, Novo Nordisk and Sanofi-Aventis; has served on an advisory board for Merck Sharp \& Dohme and Sanofi-Aventis, NovoNordisk, Boehringer Ingelheim, Novartis and Pfizer; and has received research grants from NovoNordisk. Khier Djaballah is a Sanofi employee. Shih-Te Tu has received speaking honoraria from AstraZeneca, Boehringer Ingelheim, Eli Lilly, MSD, Novartis, Novo Nordisk and Sanofi; research support from AstraZeneca, Boehringer Ingelheim, Eli Lilly, MSD, Novartis, Novo Nordisk and Sanofi; and is member of the advisory boards of Astra-Zeneca, Boehringer Ingelheim, Eli Lilly, Medtronic, MSD, Novartis, Novo Nordisk and Sanofi. Ambika G. Unnikrishnan has received honoraria and has participated in clinical trials of Novo Nordisk, Sanofi, Eli Lilly and other pharmaceutical companies. Kamlesh Khunti has served as a consultant for and received speaker fees from Amgen, AstraZeneca, Bayer, BerlinChemie AG/Menarini Group, Boehringer Ingelheim, Eli Lilly, Merck Sharp \& Dohme, NAPP, Novartis, Novo Nordisk, Roche, Sanofi-Aventis and Servier; has served on advisory boards for AstraZeneca, Eli Lilly, Merck Sharp \& Dohme, Novo Nordisk and Sanofi-Aventis; has received grants in support of investigations and investigator-initiated trials from AstraZeneca, Boehringer Ingelheim, Eli Lilly, Merck Sharp \& Dohme, Novartis, Novo Nordisk, Pfizer, SanofiAventis and Servier; and acknowledges support from National Institute for Health Research (NIHR) Collaboration for Leadership in Applied Health Research and Care-East Midlands (ARCEM) and the NIHR Leicester Biomedical Research Centre. This expert opinion originated following discussions at an expert advisory board meeting for which the authors received honoraria. However, the authors received no payment from Sanofi directly or indirectly (through a third party) related to the development of this publication and are individually and collectively responsible for all content and editorial decisions.

Compliance with Ethical Guidance. This article is based on previously conducted studies and does not contain any studies with human participants or animals performed by any of the authors.

Data Availability. Data sharing is not applicable to this article as no datasets were generated or analyzed during the current study.

Open Access. This article is licensed under a Creative Commons Attribution-NonCommercial 4.0 International License, which permits any non-commercial use, sharing, adaptation, distribution and reproduction in any medium or format, as long as you give appropriate credit to the original author(s) and the source, provide a link to the Creative Commons licence, and indicate if changes were made. The images or other third party material in this article are included in the article's Creative Commons licence, unless indicated otherwise in a credit line to the material. If material is not included in the article's Creative Commons licence and your intended use is not permitted by statutory regulation or exceeds the permitted use, you will need to obtain permission directly from the copyright holder. To view a copy of this licence, visit http://creativecommons.org/licenses/by$\mathrm{nc} / 4.0 /$.

\section{REFERENCES}

1. International Diabetes Federation (IDF). IDF diabetes atlas, 9th edn. Brussels: IDF. 2019 http://www. diabetesatlas.org. Accessed 02 April 2021.

2. Davies MJ, D'Alessio DA, Fradkin J, et al. Management of hyperglycaemia in type 2 diabetes, 2018. A consensus report by the American Diabetes Association (ADA) and the European Association for the Study of Diabetes (EASD). Diabetologia. 2018;61(12):2461-98.

3. NCD Risk Factor Collaboration (NCD-RisC). Worldwide trends in diabetes since 1980: a pooled analysis of 751 population-based studies with 4.4 
million participants. Lancet. 2016;387(10027): 1513-30.

4. Harding JL, Pavkov ME, Magliano DJ, Shaw JE, Gregg EW. Global trends in diabetes complications: a review of current evidence. Diabetologia. 2019;62(1):3-16.

5. Gagliardino JJ, Atanasov PK, Chan JC, et al. Resource use associated with type 2 diabetes in Africa, the Middle East, South Asia, Eurasia and Turkey: results from the International Diabetes Management Practice Study (IDMPS). BMJ Open Diabetes Res Care. 2017;5(1):e000297.

6. Aschner P, Gagliardino JJ, Ilkova H, et al. Persistent poor glycaemic control in individuals with type 2 diabetes in developing countries: 12 years of realworld evidence of the International Diabetes Management Practices Study (IDMPS). Diabetologia. 2020;63(4):711-21.

7. Chan JC, Gagliardino JJ, Baik SH, et al. Multifaceted determinants for achieving glycemic control: the International Diabetes Management Practice Study (IDMPS). Diabetes Care. 2009;32(2):227-33.

8. Ringborg A, Cropet C, Jönsson B, Gagliardino JJ, Ramachandran A, Lindgren P. Resource use associated with type 2 diabetes in Asia, Latin America, the Middle East and Africa: results from the International Diabetes Management Practices Study (IDMPS). Int J Clin Pract. 2009;63:997-1007.

9. Casciano R, Malangone E, Ramachandran A, Gagliardino JJ. A quantitative assessment of patient barriers to insulin. Int J Clin Pract. 2011;65(4): 408-14.

10. Gagliardino JJ, Aschner P, Baik SH, et al. Patients' education, and its impact on care outcomes, resource consumption and working conditions: data from the International Diabetes Management Practices Study (IDMPS). Diabetes Metab. 2012;38(2):128-34.

11. Al Mansari A, Obeid Y, Islam N, Fariduddin M, Hassoun A, Djaballah K, et al. GOAL study: clinical and non-clinical predictive factors for achieving glycemic control in people with type 2 diabetes in real clinical practice. BMJ Open Diabetes Res Care. 2018;6(1):e000519.

12. International Diabetes Management-Practices Study (IDMPS). International Diabetes Management-Practices Study 2017. http://www.idmps.org/ en/. Accessed 14 September 2020.

13. Zoungas S, Woodward M, Li Q, et al. Impact of age, age at diagnosis and duration of diabetes on the risk of macrovascular and microvascular complications and death in type 2 diabetes. Diabetologia. 2014;57(12):2465-74.

14. Herrington WG, Alegre-Diaz J, Wade R, et al. Effect of diabetes duration and glycaemic control on 14-year cause-specific mortality in Mexican adults: a blood-based prospective cohort study. Lancet Diabetes Endocrinol. 2018;6(6):455-63.

15. Ali MK, Bullard KM, Saaddine JB, Cowie CC, Imperatore G, Gregg EW. Achievement of goals in U.S. diabetes care, 1999-2010. N Engl J Med. 2013;368(17):1613-24.

16. Stone MA, Charpentier G, Doggen K, et al. Quality of care of people with type 2 diabetes in eight European countries: findings from the Guideline Adherence to Enhance Care (GUIDANCE) study. Diabetes Care. 2013;36(9):2628-38.

17. Khunti K, Wolden ML, Thorsted BL, Andersen M, Davies MJ. Clinical inertia in people with type 2 diabetes: a retrospective cohort study of more than 80,000 people. Diabetes Care. 2013;36(11):3411-7.

18. Wu N, Aagren M, Boulanger L, Friedman M, Wilkey K. Assessing achievement and maintenance of glycemic control by patients initiating basal insulin. Curr Med Res Opin. 2012;28(10):1647-56.

19. Blonde L, Aschner P, Bailey C, et al. Gaps and barriers in the control of blood glucose in people with type 2 diabetes. Diab Vasc Dis Res. 2017;14(3): $172-83$

20. Khunti K, Damci T, Meneghini L, Pan CY, Yale JF, SOLVE Study Group. Study of Once Daily Levemir $\left(\mathrm{SOLVE}^{\mathrm{TM}}\right)$ : insights into the timing of insulin initiation in people with poorly controlled type 2 diabetes in routine clinical practice. Diabetes Obes Metab. 2012;14(7):654-61.

21. Russell-Jones D, Pouwer F, Khunti K. Identification of barriers to insulin therapy and approaches to overcoming them. Diabetes Obes Metab. 2018;20(3):488-96.

22. Aschner P, Gagliardino JJ, Ilkova H,et al. Reasons for discontinuation of insulin therapy-results from the International Diabetes Management Practices Study (IDMPS). Diabetes. 2018;67 (Suppl 1). https://doi.org/10.2337/db18-1026-P.

23. Morrish NJ, Wang SL, Stevens LK, Fuller JH, Keen H. Mortality and causes of death in the WHO multinational study of vascular disease in diabetes. Diabetologia. 2001;44(Suppl 2):S14-21.

24. Roglic G, Unwin N. Mortality attributable to diabetes: estimates for the year 2010. Diabetes Res Clin Pract. 2010;87(1):15-9. 
25. Zaccardi F, Dhalwani NN, Webb DR, Davies MJ, Khunti K. Global burden of hypoglycaemia-related mortality in 109 countries, from 2000 to 2014: an analysis of death certificates. Diabetologia. 2018;61(7):1592-602.

26. American Diabetes Association. 10. Cardiovascular disease and risk management: standards of medical care in diabetes-2019. Diabetes Care. 2019;42(Suppl 1):S103-23.

27. American Diabetes Association. 11. Microvascular Complications and Foot Care: Standards of Medical Care in Diabetes-2019. Diabetes Care. 2019;42(Suppl 1):S124-S38.

28. Gagliardino JJ, Aschner P, Ilkova $H$, Lavalle $F$, Ambady R, Kaddaha G, et al. Frequency of diabetesrelated complications in type 1 and type 2 diabetes-Results from the International Diabetes Management Practices Study (IDMPS). Diabetes. 2018;67 (Suppl 1).

29. Aschner P, Gagliardino JJ, Ilkova $H$, Lavalle F, Ramachandran A, Mbanya JC, et al. Persistent poor glycaemic control in individuals with type 2 diabetes in developing countries: 12 years of real-world evidence of the International Diabetes Management Practices Study (IDMPS). Diabetologia. 2020;63(4):711-21.

30. Smith-Spangler CM, Bhattacharya J, GoldhaberFiebert JD. Diabetes, its treatment, and catastrophic medical spending in 35 developing countries. Diabetes Care. 2012;35(2):319-26.
31. Shobhana R, Rao PR, Lavanya A, Vijay V, Ramachandran A. Cost burden to diabetic patients with foot complications-a study from southern India. J Assoc Phys India. 2000;48(12):1147-50.

32. Pepper DJ, Levitt NS, Cleary S, Burch VC. Hyperglycaemic emergency admissions to a secondarylevel hospital-an unnecessary financial burden. S Afr Med J. 2007;97(10):963-7.

33. Zheng Y, Ley SH, Hu FB. Global aetiology and epidemiology of type 2 diabetes mellitus and its complications. Nat Rev Endocrinol. 2018;14(2):88-98.

34. Ramachandran A, Schwarzbard J, Atanasov P, et al. Cost of type 2 diabetes in urban Indian population. Value Health. 2016;19:A670.

35. Malhan S, Schwarzbard J, Sahin T, et al. Type 2 Diabetes in Turkey-a cost of illness study. Value Health. 2016;19(7):A669.

36. Kerr M, Barron E, Chadwick P, et al. The cost of diabetic foot ulcers and amputations to the National Health Service in England. Diabet Med. 2019;36(8):995-1002.

37. American Diabetes Association (ADA). The cost of diabetes 2017. https://www.diabetes.org/resources/ statistics/cost-diabetes. Accessed 02 April 2021.

38. Zimmet PZ, Magliano DJ, Herman WH, Shaw JE. Diabetes: a 21st century challenge. Lancet Diabetes Endocrinol. 2014;2(1):56-64. 